\title{
GCU
}

Glasgow Caledonian

University

University for the Common Good

\section{A canopy flow equation for erosion control geosynthetics}

Hytiris, Nicholas; McKay, D. J.; Addison, P. S.

Published in:

Geosynthetics International

Publication date:

2001

Document Version

Publisher's PDF, also known as Version of record

Link to publication in ResearchOnline

Citation for published version (Harvard):

Hytiris, N, McKay, DJ \& Addison, PS 2001, 'A canopy flow equation for erosion control geosynthetics',

Geosynthetics International, vol. 8, no. 3, pp. 221-232. <http://www.icevirtuallibrary.com/content/journals>

\section{General rights}

Copyright and moral rights for the publications made accessible in the public portal are retained by the authors and/or other copyright owners and it is a condition of accessing publications that users recognise and abide by the legal requirements associated with these rights.

Take down policy

If you believe that this document breaches copyright please view our takedown policy at https://edshare.gcu.ac.uk/id/eprint/5179 for details of how to contact us. 


\title{
Technical Paper by N. Hytiris, D.J. McKay, and P.S. Addison A CANOPY FLOW EQUATION FOR EROSION CONTROL GEOSYNTHETICS
}

\begin{abstract}
A novel experimental test programme for erosion control geosynthetic mattings, i.e., geomats, is described. Using a laser Doppler anemometer, the velocities have been examined within the flow field at the fluid-geomat interface. Initial analysis of the test results has lead to a modified log-law equation for the downstream flow velocities above the geomat. This equation has the same form as canopy flow equations used in meteorology to describe the velocity profiles above vegetative canopies in the atmospheric boundary layer. The canopy flow equation for erosion control geotextiles is discussed herein.
\end{abstract}

KEYWORDS: Erosion control, Geomat, Laser Doppler anemometery, Hydraulic, Velocity distribution profile, Log-law, Canopy flow, Roughness coefficient.

AUTHORS: N. Hytiris, Senior Lecturer, Department of Energy and Environmental Technology, Glasgow Caledonian University, Glasgow, Scotland, United Kingdom, Telephone: 44/141-331-3686, Telefax: 44/141-331-3370, E-mail: N. Hytiris@gcal.ac.uk; D.J. McKay, Doctoral candidate, Department of Energy and Environmental Technology, Glasgow Caledonian University, Glasgow, Scotland, United Kingdom, Telephone: 44/141-331-3590, E-mail: djsmckay@hotmail.com; and P.S. Addison, Senior Lecturer, School of the Built Environment, Napier University, Edinburgh, Scotland, United Kingdom, Telephone: 44/131-455-2302, Telefax: 44/131-4552239, E-mail: P.Addison@napier.ac.uk.

PUBLICATION: Geosynthetics International is published by the Industrial Fabrics Association International, 1801 County Road B West, Roseville, Minnesota 551134061, USA, Telephone: 1/612-222-2508, Telefax: 1/612-631-9334. Geosynthetics International is registered under ISSN 1072-6349.

DATE: Original manuscript submitted 18 July 2000, revised version received 9 April 2001, and accepted 12 April 2001. Discussion open until 1 January 2002.

REFERENCE: N. Hytiris, D.J. McKay, and P.S. Addison, 2001, "A Canopy Flow Equation For Erosion Control Geosynthetics", Geosynthetics International, Vol. 8, No. 3, pp. 221-232. 


\section{INTRODUCTION}

Over the past four decades, geosynthetics have become commonplace in the engineering world. As the name implies, geosynthetics are almost exclusively made of manmade fibres for use with geotechnically related materials (e.g., soil and rock). All geosynthetics can be classified under one of five main functions such as reinforcement, separation, liquid barrier, drainage, or filtration geosynthetics (Koerner 1994). Recent years have seen a rapid growth in their use in the field of erosion control where they separate the soil from atmospheric conditions. However, the relatively new method of erosion control using geotextiles has no rigorous methodology of either design or testing that encompasses all the geometric forms of geomats currently in use.

In the study described in the present paper, four commercially available erosion control geomats were tested. These erosion control revegetation geomats (ECRMs) are all in the specific category of turf reinforcement and, hence, are generally termed turf reinforcement mattings (TRMs) (Koerner 1994; Theisen 1995). TRMs take the form of open-structure, three-dimensional polymer geosynthetics of various densities and contexture. Although the geometric structure varies for all the geomats studied, they have the same function, namely, to:

- provide temporary protection to bare soil during the development of vegetation, and

- provide permanent reinforcement to fully developed vegetation, allowing for the turf to withstand significantly higher loads than the unprotected state.

The experiments were set up to examine the flow field for the four geomats during initial geomat placement, where vegetation did not have time to grow within the mat structure. The experiments were conducted in an experimental flume lined with each geomat in turn. A one-dimensional laser Doppler anemometer was used to provide a detailed downstream velocity time series at locations throughout the depth of flow.

A prior pilot study (McKay et al. 1999) had shown that the velocity profile for a random filament geomat was displaced upwards from the actual flume bed to a level corresponding to an apparent main filament strata. This level could easily be described as a "virtual bottom" (Chow 1973), "effective bed", or "theoretical bottom" (Bayazit 1976) and was initially thought, by the authors, to have been produced by a specific formation of filaments within the tested geomat. The testing discussed herein was initiated to investigate whether an effective/virtual/theoretical base (the level of displacement of the velocity profile) was present in all forms of geomat despite structural differences.

\section{EXPERIMENTAL SETUP AND CONDITIONS}

The experiments were conducted in a $4 \mathrm{~m}$-long, $0.6 \mathrm{~m}$-wide, glass panel, tilting flume. For all of the tests, the slope was kept constant at $1 \times 10^{-4}$ for the bare channel and the flow rate was kept at a constant 6 litres per second. A constant depth of $0.1 \mathrm{~m}$ was attained in the channel using the adjustable tailgate of the flume and was measured via the gauges mounted on the top of the flume. The various synthetic materials, when present, covered 
HYTIRIS, McKAY \& ADDISON • Canopy Flow Equation for Erosion Control Geosynthetics

the entire flume bed and were secured at regular intervals using wire ties.

The instantaneous streamwise velocity components were measured using a onedimensional (1-D) Dantec LDA system and processed by the supporting personal computer and its software (FloLite 1991). The laser probe was placed $\geq 2 \mathrm{~m}$ downstream of the inlet tank and was situated underneath the flume on a traverse/support accurate to within $\pm 0.1 \mathrm{~mm}$ (Keogh and Addison 1996) for all directions of travel, which enabled readings to be taken vertically throughout the flow depth.

The laser system was set up to obtain 3,000 samples per location and, for each depth, three sample sets were obtained per run such that an average of 9,000 samples per depth reading was achieved per run. To obtain a good representation of the flow near the base, samples were taken every millimetre interval between $0 \mathrm{~mm} \leq y \leq 10$ $\mathrm{mm}$, then every two millimetre interval between $10 \mathrm{~mm} \leq y \leq 22 \mathrm{~mm}$. Within the main flow, readings were taken every $5 \mathrm{~mm}$ interval between $25 \mathrm{~mm} \leq y \leq 50 \mathrm{~mm}$ and every $10 \mathrm{~mm}$ interval between $50 \mathrm{~mm} \leq y \leq 90 \mathrm{~mm}$ with two final readings at 96 and $98 \mathrm{~mm}$.

The geomats used in the present study, as mentioned above, covered the wide range of designs currently used in industry from around the world (Table 1).

\section{EXPERIMENTAL RESULTS AND ANALYSIS}

\subsection{Introduction}

Initial control tests consisting of runs in the channel without an erosion control geomat present were undertaken. The results show that the bare channel conditions are consistent with the theoretical expectations of fully formed flow (Figure 1). These results were used to determine the effect of the geomat presence on flow within the flume.

All of the geomat experimental velocity profiles are presented in Figure 2. All of the profiles show similar results of a traditional-looking logarithmic profile, displaced toward a depth nearing that of the nominal geomat thickness, with a seemingly linear drop toward the base level and zero velocity. This is the case for the majority of geomats except Geomat 2, which differs due to poor structural integrity.

Table 1. Physical properties of the geomats.

\begin{tabular}{|c|c|c|c|c|c|}
\hline Product & $\begin{array}{c}\text { Nominal } \\
\text { thickness } \\
(\mathrm{mm})\end{array}$ & $\begin{array}{l}\text { Polymer } \\
\text { type }\end{array}$ & $\begin{array}{c}\text { Mass per } \\
\text { unit area } \\
\left(\mathrm{g} / \mathrm{m}^{2}\right)\end{array}$ & $\begin{array}{c}\text { Tensile } \\
\text { strength } \\
(\mathrm{kN} / \mathrm{m})\end{array}$ & $\begin{array}{c}\text { General } \\
\text { description }\end{array}$ \\
\hline Geomat 1 & 18 & Polyethylene & 450 & 3.2 & $\begin{array}{l}\text { Cuspated "egg-box" meshes, heat- } \\
\text { bonded to flat-base meshes }\end{array}$ \\
\hline Geomat 2 & 17 & Polypropylene & 320 & 10 & $\begin{array}{c}\text { Corrugated mesh sown between two } \\
\text { layers of flat mesh }\end{array}$ \\
\hline Geomat 3 & 18 & Polyamide 6 & 407 & 2.3 & $\begin{array}{l}\text { Open form, heat-bonded, random } \\
\text { monofilament structure }\end{array}$ \\
\hline
\end{tabular}




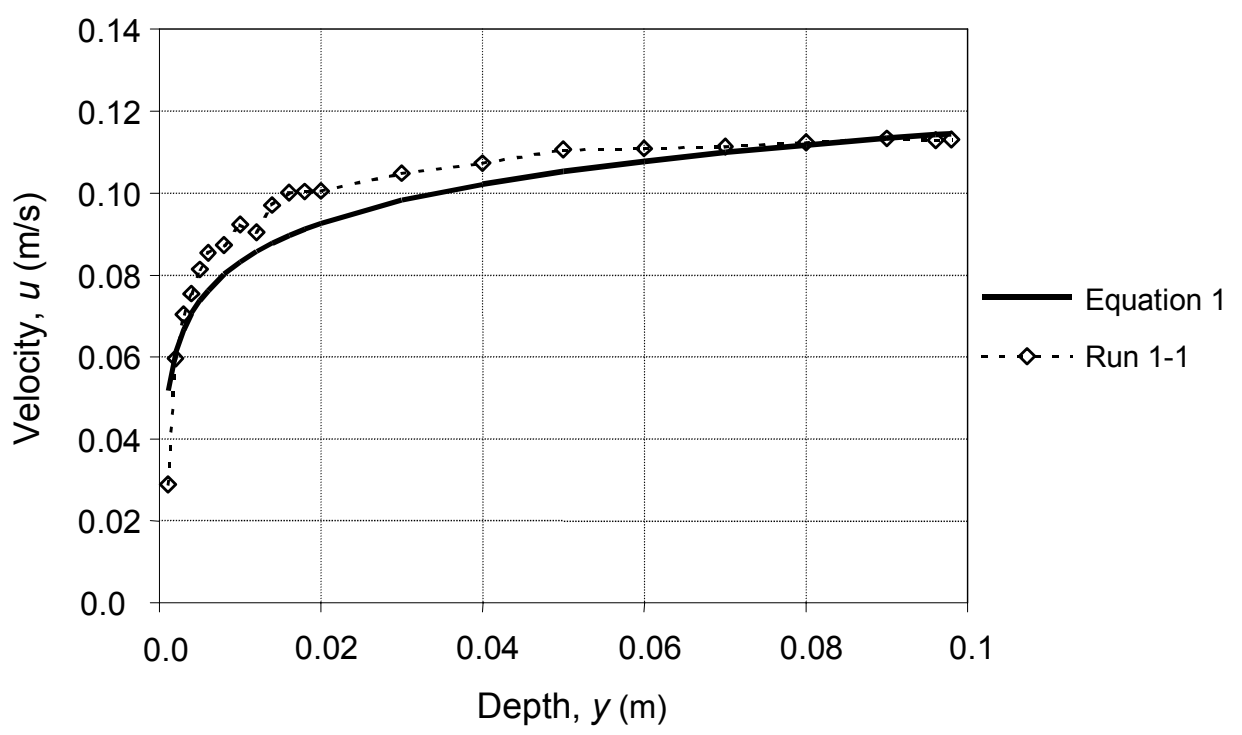

Figure 1. Bare channel velocity profile.

The authors of the present paper discovered that flow bounded by the geomat region contained approximately $4 \%$ of the overall flow for the whole channel. The average velocity in the over-mat flow region could be calculated by removing this $4 \%$ and the geomat thickness from the overall flow rate and depth, respectively, of a traditional Bernoulli velocity/flow rate equation. Attempting to similarly compensate in the logarithmic "law of the wall" equation yielded no results. However, it was known that the experimental profiles were logarithmic and this lead to the main focus of the study - to produce a logarithmic law for geomat flow.

\subsection{Analysis: Logarithmic "Law of the Wall"}

\subsubsection{General Information}

For the present study, velocity analysis results were evaluated using the "law of the wall" (Equation 1), which has been used successfully for many years (Bayazit 1976; Tani 1977; Nezu and Nakagawa 1993; Nezu and Rodi 1986) within the study of open channel flows. It was used within the present study to measure the formation of flow within the control test of the bare channel (Figure 1).

$$
\frac{u}{u^{*}}=\frac{1}{\kappa} \ln \eta+B
$$

where: $u^{*}=$ shear velocity, which can be estimated from $u^{*}=\sqrt{g R s}$ during normal conditions ( $g=$ acceleration due to gravity, $R=$ hydraulic radius, $s=$ bed slope); $\kappa=$ 
(a)
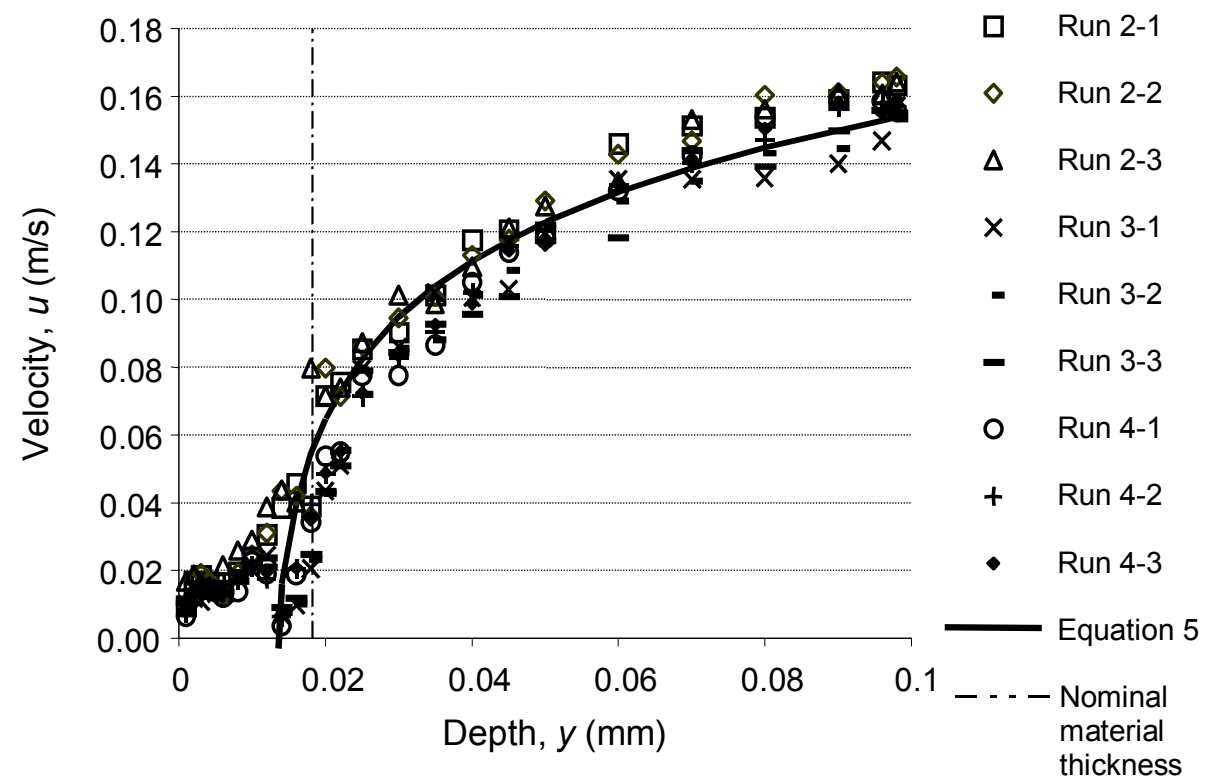

(b)
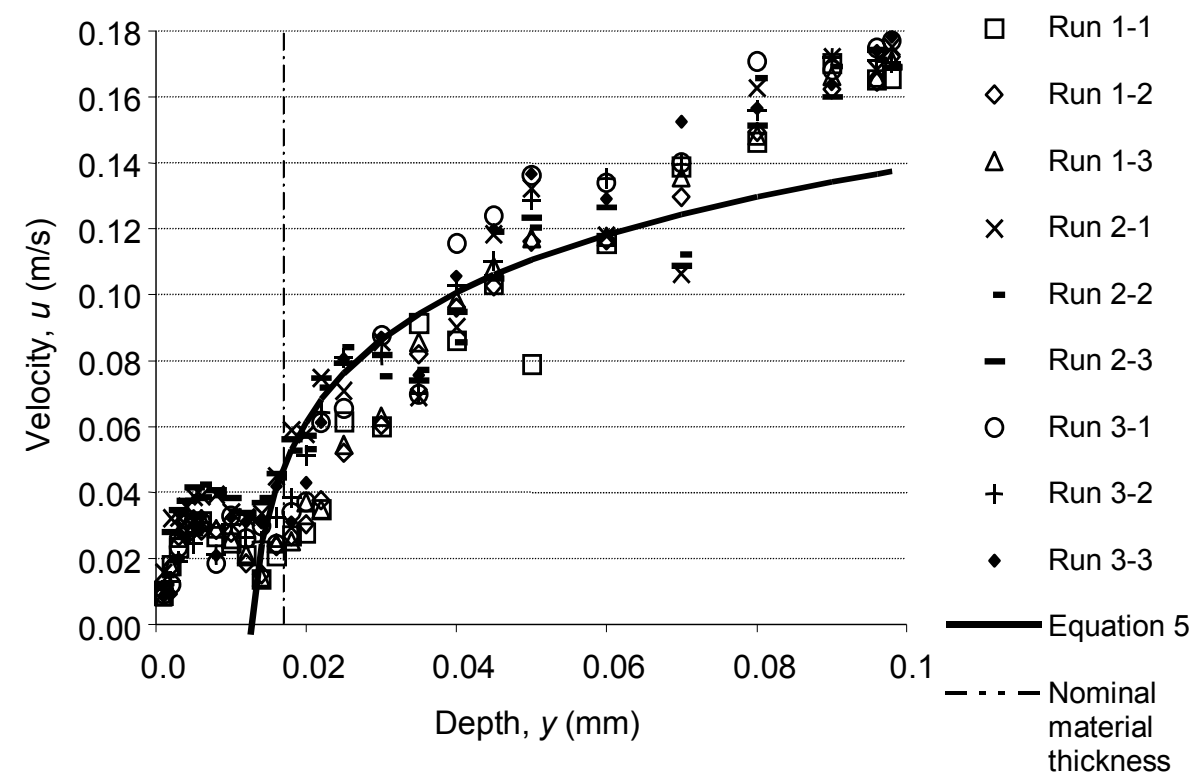

Figure 2. Velocity profiles for the different geomats: (a) Geomat 1; (b) Geomat 2. 
(c)

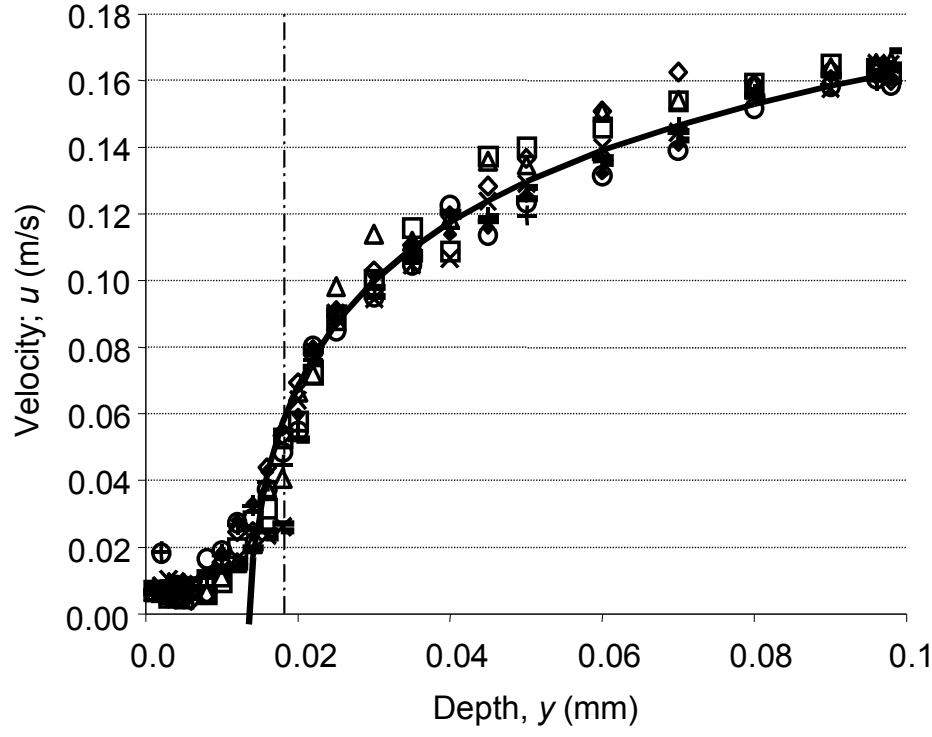

(d)

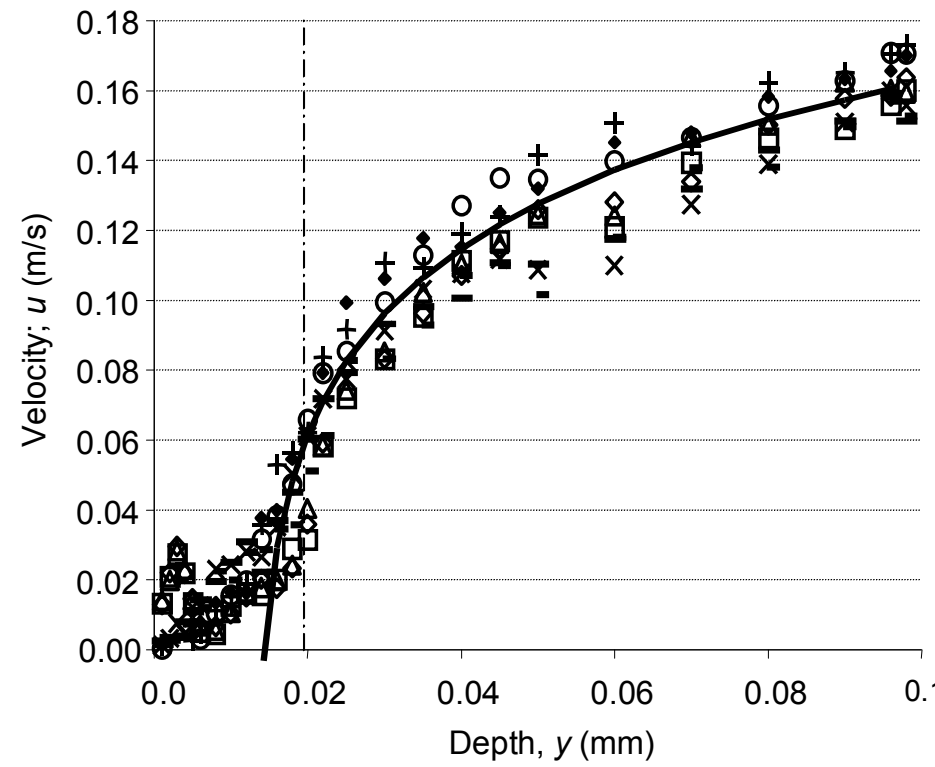

Figure 2 continued. (c) Geomat 3; (b) Geomat 4. $\square \quad$ Run 3-1

$\diamond \quad$ Run 3-2

$\Delta \quad$ Run 3-3

$\times \quad$ Run 4-1

- $\quad$ Run 4-2

- $\quad$ Run 4-3

O Run 5-1

$+\quad$ Run 5-2

- $\quad$ Run 5-3

Equation 5

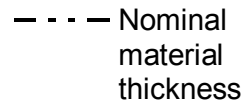
thickness

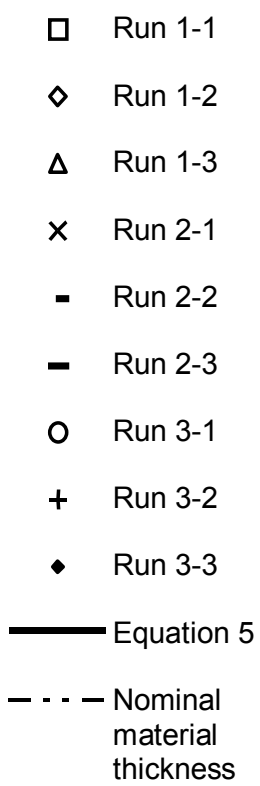

ㅁ Run 1-1

$\diamond \quad$ Run 1-2

$\Delta \quad$ Run $1-3$

(2)

Run 3-3 thickness 
HYTIRIS, McKAY \& ADDISON • Canopy Flow Equation for Erosion Control Geosynthetics

Von Karman constant $=0.41$ under most circumstances (but has been noted within the ranges of 0.16 to 0.41 (Yalin 1972)); $\eta=$ scaled length $\left(=y u^{*} / v\right.$ for smooth conditions and $y k_{s}$ for rough conditions, where $y=$ depth from base level, $v=$ kinematic viscosity, and $k_{s}=$ Nikuradse effective sand roughness coefficient); and $B=$ constant $=8.5$ for rough conditions and 5.5 for smooth conditions.

There are a few problems when using Equation 1 for geomat-lined open channels. For the traditional open-channel log-law equation, the Nikuradse effective sand roughness coefficient, $k_{s}$, does not take into account the thick permeable roughness of the geomats. Therefore, the theoretical profile does not produce the displacement of the base line caused by the permeable structure of the geomats.

Many studies of the roughness effect on the logarithmic distribution equation and the roughness factor (Einstein and Barbarossa 1952; Antonia 1971; van Rijn 1982; Hey 1979; Ackers and White 1973) have been completed; however, all of these studies relate to the roughness of impermeable particles. The authors of the present paper attempted to provide a fit to the measured velocity profiles by modifying the log-law equation, which resulted in the following:

$$
\begin{gathered}
\frac{u}{u^{*}}=\frac{1}{\kappa} \ln \left(\frac{y-h_{g}}{k_{g}}\right)+B \\
\frac{u}{u^{*}}=\frac{1}{\kappa} \ln \left(\frac{y-h_{g}}{k_{g} / A_{B}}\right)
\end{gathered}
$$

where: $h_{g}=$ "virtual bottom" depth, which is the depth of displacement of flow produced by the presence of a geomat (the value of $h_{g}$ was estimated to be between $y=$ 0.011 to 0.017 for geomat thicknesses ranging from $y=0.018$ to 0.020$) ; k_{g}=$ geomat/ bed roughness coefficient; and

$$
A_{B}=\exp ^{(\kappa B)}
$$

Although Equation 2 provides a fit to the experimental data, empirical and/or statistical analysis must then be used to calculate the best-fit of various variables (namely, $u^{*}, h_{g}$, and $k_{g}$ ). This appeared troublesome and led the authors of the present paper to study the micrometeorological canopy flow in the hope that theoretical solutions for the parameters could be premeditated.

\subsubsection{Analysis: Canopy Flow}

Due to the discrete, permeable nature of geomats, the effective roughness was seen to be a parameter that would be difficult to evaluate. This lead to the study of previous works on the subject of roughness and, in turn, to the observation that the geomat profiles were similar to those produced for vegetated hydraulic channels and studies of micrometeorology canopy flow (Nezu and Onitsuka 1999; Thom 1971; Jackson 1981; Cionco 1972).

The study of micrometeorological canopy flow showed that Equation 3 is a canopy 
flow equation. The logarithmic canopy flow equation takes the following form:

$$
u(z)=\frac{u^{*}}{\kappa} \ln \left(\frac{y-d}{z_{o}}\right)
$$

where: $d=$ zero plane displacement, normally taken as $d=0.64 h$, with $h=$ canopy depth; and $z_{o}=$ roughness length equal to $0.36(h-d)$. The zero plane displacement calculation is similar to the theoretical bottom suggested by Bayazit (1976) for a bed of hemispherical particles located at a distance of $35 \%$ of a diameter from the top of the roughness elements. Comparing Equation 5 with Equation 3, shows that Equation 3 is a canopy flow equation.

The authors of the present paper altered the calculation of roughness length for Equation 5 assuming it is equivalent to $k_{g} / A_{B}$ from Equation 3, in an attempt to model the flow measured during the tests. A best-fit of the theoretical data to the experimental results was possible by assuming the following: (i) the shear velocity value, $u^{*}=\sqrt{g d s}$; (ii) the depth of the virtual bottom (displacement depth), $d$, being equal to $0.65 h$ ( $h$ being the nominal geomat thickness); and (iii) $z_{o}=k_{g} / A_{B}$ (Figures $2 \mathrm{a}$ to $2 \mathrm{~d}$ ).

Through analysis of the theoretical and empirical results, it was possible to formulate the following equation for the effective roughness of the geomats:

$$
k_{g}=2.5 h
$$

Equation 6 resembles the suggested average values of the Nikuradse effective sand roughness of $3 D_{90}$ (van Rijn 1982), where $D_{90}$ is a sand diameter. The theoretical profile can then be fitted by varying "Manning's $n$ " in the channel condition equation for calculating slopes - the Manning equation (Gauckler-Manning) (Chow 1973; Chanson 1999):

$$
Q=\frac{1}{n} \frac{A^{5 / 3}}{p^{2 / 3}} \sqrt{s}
$$

\section{CONCLUSIONS}

Equation 2 provided a fit with test data velocity profiles (with exception of Figure 2d, due to geomat structural integrity); however, Equation 2 was determined to be unsuitable in its natural state because it required empirical variables that could dramatically differ depending on the calculation methods. The derivation of the "canopy flow" law (Equation 5) produced variables calculated using accepted theoretical formulae (for $d$ and $k_{g}$, Equation 7). These variables, when used in conjunction with either Equations 2, 3 , or 5, allowed the profiles to be fitted by the alteration of a single value: Manning's roughness coefficient, $n$. Values of Manning's roughness for different surfaces have previously been measured and are, thus, widely available in the literature. However, due to the complicated nature of the flow physics within the internal geomat structure, canopy law equations are not valid within the geomat region, and separate exponential equa- 
tions must be implemented to produce theoretical distributions in this interfacial zone.

The calculation of the geomat effective roughness, $k_{g}=2.5 h$, agrees with the conclusions of previous studies (Bayazit 1976; van Rijn 1982) and the suggested values of effective roughness for rough beds (if one assumes the roughness depth $h$ is equivalent to a sand diameter). However, contrary to many other works on the subject of roughness, which commonly deal with sand/spherical roughness elements and suggest discrete roughness should not be treated in the same manner as sand roughness, the present study shows that, although the roughness is discrete, the overall effect on the flow characteristics are not dissimilar and actually allow for treatment of effective roughness in the manner of traditional sandy rough beds.

The pilot study for the present study concluded that there was a virtual/theoretical bottom present within the geomat structure. This is now supported by the conclusion that flow over and within erosion control geomats produces microscale canopy flow, which can be seen from one specific set data (Figure 3). This data set shows the velocity profile over a geomat, which was not properly secured to the flume base. This allowed for the matting to rise off the flume bed and induced increased velocities in the region between the geomat and base. This can be said to model the effect of the foliage-free tree-trunk zone within a forest, which produces similar results. This phenomenon also highlights the importance of correct geomat placement as it could mean increased erosion below the geomat, which, in turn, could result in system failure.

These conclusions also reinforce the fact that it is the roughness factors that are of importance in the design of erosion control geomats, with Manning's roughness remaining the solitary function that affects the theoretical solution and the roughness length being the critical function within the velocity distribution equations. The roughness/ effective roughness will be investigated in the planned next stage of the testing programme. This stage will investigate the most effective formation of filament structure on

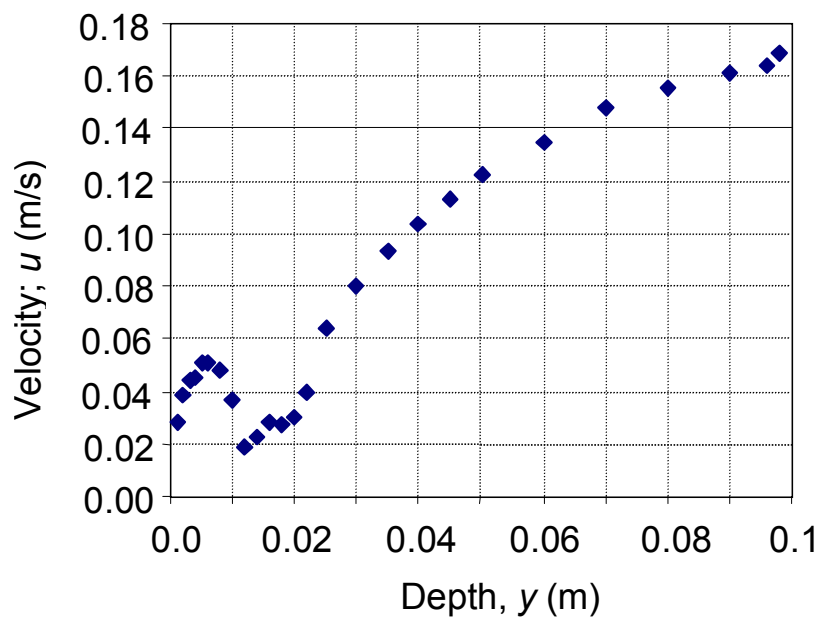

Figure 3. Velocity profile with under-mat flow. 
HYTIRIS, McKAY \& ADDISON • Canopy Flow Equation for Erosion Control Geosynthetics

overall erosion control in a custom-built experimental sediment transportation facility.

Although the theory produced has not yet been fully scrutinised by extended testing, the authors of the present paper are confident that the theoretical equation for velocity profiles over geomats will lead to a better understanding of the mechanics involved when using such materials.

\section{ACKNOWLEDGEMENT}

The authors would like to thank J. Crowther, Senior Lecturer at Glasgow Caledonian University, for his guidance during the study of micro-canopy flow.

\section{REFERENCES}

Ackers, P. and White, W.R., 1973, "Sediment Transport: New Approach and Analysis", Journal of the Hydraulics Division, Vol. 99, No. HY11, pp. 2041-2060.

Antonia, R.A., 1971 "The Response of a Turbulent Boundary Layer to a Step Change in the Surface Roughness, Part 1. Smooth to Rough", Journal of Fluid Mechanics, Vol. 48, No. 4, pp. 721-761.

Bayazit, M., 1976, "Free Surface Flow in a Channel of Large Relative Roughness", Journal of Hydraulics Research, Vol. 14, Part 1, pp. 115-126.

Chanson, H., 1999, "The Hydraulics of Open Channel Flow: An Introduction", Arnold, London, $495 \mathrm{p}$.

Chow, V.T., 1973, “Open-Channel Hydraulics”, McGraw-Hill, New York, 680 p.

Cionco, R.M., 1972, "Intensity of Turbulence within Canopies with Simple and Complex Roughness Elements", Boundary Layer Meteorology, Vol. 2, pp. 453-465.

Einstein, H.A. and Barbarossa, N.L., 1952, "River Channel Roughness", ASCE Transactions No. 2528, pp. 1121-1132.

Dantec Measuring Technology, 1991, "Flolite”, FLOware, Skovlunde, Denmark, Version 3.2.

Hey, R.D., 1979, "Flow Resistance in Gravel-Bed Rivers", Journal of the Hydraulics Division, Vol. 105, No. HY4, pp. 365-379.

Jackson, P.S., 1981, "On the Displacement Height in the Logarithmic Velocity Profile", Journal of Fluid Mechanics, Vol. 111, pp. 15-25.

Keogh, D.P. and Addison, P.S., 1996, "Coherent Flow Structures in Open-channel Slot Flow”, Coherent Flow Structures, Ashworth, P.J., Bennett, S.J., Best, J.L., and McLelland, S.J., Editors, John Wiley and Sons, Chapter 14, pp. 267-280.

Koerner, R.M., 1994, "Designing with Geosynthetics", Third Edition, Prentice Hall, Englewood Cliffs, New Jersey, USA, 783 p.

McKay, D., Hytiris, N., and Addison, P.S., 1999, "Studies of Erosion Control Geomat Using Laser Doppler Anemometry", River Sedimentation: Theory and Applica- 
HYTIRIS, McKAY \& ADDISON • Canopy Flow Equation for Erosion Control Geosynthetics

tions, Jayawardena, A.W., Lee, J.H.W., and Wang, Z.Y., Editors, Balkema, Proceedings of the Seventh International Symposium on River Sedimentation, Hong Kong, China, December 1998, pp. 337-342.

Nezu, I. and Nakagawa, H., 1993, "Turbulence in Open-Channel Flows", Balkema, Rotterdam, $281 \mathrm{p}$.

Nezu, I. and Onitsuka, K., 1999, “3-D Turbulent Structures in Partly Vegetated OpenChannel Flows", Environmental Hydraulics, Lee, J.H.W., Jayawardena, A.W., and Wang, Z.Y., Editors, Balkema, Proceedings of the Second International Symposium on Environmental Hydraulics, Hong Kong, China, December 1998, pp. 305310 .

Nezu, I. and Rodi, W., 1986, “Open Channel Flow Measurements with a Laser Doppler Anemometer”, Journal of Hydraulic Engineering, Vol. 112, No. 5, pp. 115119.

van Rijn, L.C., 1982, “Equivalent Roughness of Alluvial Bed”, Journal of the Hydraulics Division, Vol. 108, No. HY10, pp. 1215-1218.

Tani, I., 1977, "History of Boundary-Layer Theory”, Annual Review of Fluid Mechanics, Vol. 9, pp. 87-111.

Theisen, M.S., 1995, “The Role of Geosynthetics in Erosion and Sediment Control: An Overview”, Geotextiles and Geomembranes, Vol. 11, pp. 535-550.

Thom, A.S., 1971, "Momentum Absorption by Vegetation", Quarterly Journal of the Royal Meteorological Society, Vol. 97, pp. 414-428.

Yalin, M.S., 1972, “Mechanics of Sediment Transport”, Pergamon Press, Oxford; New York: Pergamon Press, 290 p.

\section{NOTATIONS}

Basic SI units are given in parentheses.

$\begin{array}{ll}A_{B}, B & =\text { logarithmic constant (dimensionless) } \\ D_{90} & =\text { particle diameter for which } 90 \% \text { of soil sample is smaller }(\mathrm{m}) \\ d & =\text { displacement depth/virtual bottom depth }(=0.64 h) \\ g & =\text { acceleration due to gravity }\left(\mathrm{m} / \mathrm{s}^{2}\right) \\ h & =\text { canopy/nominal geomat depth }(\mathrm{m}) \\ h_{g} & =\text { virtual bottom depth/effective geomat thickness }(\mathrm{m}) \\ k_{g} & =\text { effective geomat roughness }(\mathrm{m}) \\ k_{S} & =\text { Nikuradse effective sand roughness }(\mathrm{m}) \\ n & =\text { Manning's roughness coefficient }(\text { dimensionless }) \\ Q & =\text { flow rate }\left(\mathrm{m}^{3} / \mathrm{s}\right)\end{array}$


HYTIRIS, McKAY \& ADDISON • Canopy Flow Equation for Erosion Control Geosynthetics

$\begin{array}{lll}R & =\text { hydraulic radius }(\mathrm{m}) \\ s & =\text { bed slope (dimensionless) } \\ u, u(z) & =\text { velocity at depth } y \text { or } z \text { (in micrometeorology) }(\mathrm{m} / \mathrm{s}) \\ u^{*} & =\text { shear velocity }(\mathrm{m} / \mathrm{s}) \\ y & =\text { depth from base level }(\mathrm{m}) \\ z_{o} & =\text { roughness length }(\mathrm{m}) \\ \eta & =\text { scaled length }(\mathrm{m}) \\ \kappa & =\text { von Karman constant }(\text { dimensionless }) \\ v & =\text { kinematic viscosity }\left(\mathrm{m}^{2} / \mathrm{s}\right)\end{array}$

